\title{
T cell exhaustion is associated with the risk of papillary thyroid carcinoma and can be a predictive and sensitive biomarker for diagnosis
}

Chumeng Zhu ${ }^{1,2+}$, Yuechu Dai ${ }^{3+}$, Hui Zhang ${ }^{4+}$, Yanyun Ruan ${ }^{1}$, Yong Zhou ${ }^{5}$, Yingjie Dai ${ }^{5}$, Lilong Fan ${ }^{4}$, Tianjun Jia $^{2 *}$, Hongsheng $\mathrm{Lu}^{4^{*}}$ and Qi Chen ${ }^{1^{*}}$ (i)

\begin{abstract}
Background: The incidence of papillary thyroid carcinoma (PTC) has been steadily increasing over the past decades. Hashimoto's thyroiditis (HT) is the most common autoimmune disease, and is related to the pathogenesis of PTC. Programmed death-1 (PD-1) is currently used for the treatment of PTC, but there are very few studies on the clinical value of PD-1 in the diagnosis and targeted therapy of PTC.

Methods: The expression of T, B, NK cells and PD-1 in the peripheral blood of 132 patients with PTC (PTC group), 48 patients with nodular goiter (NG group) and 63 healthy subjects (HP group) were detected by flow cytometry. The expression of plasma T3, T4, FT3, FT4, TSH, TGAb and TPO was detected by chemiluminescence immunoassay. Among 132 PTC, 49 PTC\&HT and 83 PTC\&noHT were included. Among 48 NG, 10 NG\&HT and 38 NG\&noHT were included. The expressions of programmed death- ligand1(PD-L1) in tumor tissues of PTC group and thyroid tissues of NG group, PD-1 and CD3 in tumor infiltration lymphocyte (TIL) were detected by immunohistochemistry.

Results: The expression of $\mathrm{FT} 3, \mathrm{TGAb}, \mathrm{CD}^{+} \mathrm{PD}-1^{+}, \mathrm{CD}^{+} \mathrm{CD}^{+} \mathrm{PD}-1^{+}$and $\mathrm{CD} 3^{+} \mathrm{CD} 8^{+} \mathrm{PD}-1^{+}$in PTC and $\mathrm{NG}$ was significantly higher than that in the HP group. Moreover, $\mathrm{CD}^{+} \mathrm{PD}-1^{+}, \mathrm{CD}_{3}{ }^{+} \mathrm{CD} 4^{+} \mathrm{PD}-1^{+}$and $\mathrm{CD} 3^{+} \mathrm{CD} 8^{+} \mathrm{PD}-1^{+}$ expression had significant differences between the PTC group and the NG group. In addition, the expression of $\mathrm{TGAb}, \mathrm{TPO}, \mathrm{CD}^{+} \mathrm{PD}-1^{+}, \mathrm{CD}^{+} \mathrm{CD}^{+} \mathrm{PD}-1^{+}$and $\mathrm{CD} 3^{+} \mathrm{CD} 8^{+} \mathrm{PD}-1^{+}$in PTC\&HT group was significantly higher than that in the PTC\&noHT group. While, the expression of $\mathrm{B}$ cells, $\mathrm{CD} 3^{+} \mathrm{PD}-1^{+}, \mathrm{CD}^{+} \mathrm{CD}^{+} \mathrm{PD}-1^{+}$and $\mathrm{CD} 3^{+} \mathrm{CD} 8^{+} \mathrm{PD}-1^{+}$in PTC\&HT group was higher than that in NG\&HT group. PD-1 showed a significant correlation with PTC lymph node metastasis. $\mathrm{CD}^{+} \mathrm{PD}-1^{+}$and $\mathrm{CD} 3^{+} \mathrm{CD} 4^{+} \mathrm{PD}-1^{+}$was higher in $\mathrm{N} 1$ stage than in $\mathrm{N} 0$ stage. Immunohistochemical results showed that the expression of PD-1, CD3 and PD-L1 in PTC was significantly higher than that in NG.
\end{abstract}

\footnotetext{
*Correspondence: tjjia1968@163.com; luhs@tzc.edu.cn; chenqi7997@163.com

${ }^{+}$Chumeng Zhu, Yuechu Dai and Hui Zhang contributed equally to this work.

${ }^{2}$ College of Lab Medicine, Hebei North University, No.11, Zuanshi Road

(south), Gaoxin District, Zhangjiakou 075000, Hebei, People's Republic of

China

${ }^{4}$ Department of Pathology, Taizhou Central Hospital (Taizhou University Hospital), Taizhou, 31800 Zhejiang, People's Republic of China

${ }^{1}$ Precision Medicine Center, Taizhou Central Hospital (Taizhou University Hospital), Taizhou 318000, Zhejiang, People's Republic of China

Full list of author information is available at the end of the article
} 
Conclusions: $T$ cell exhaustion might act as a biomarker for the differential diagnosis of PTC and NG. Patients with PTC\&HT have obvious T cell exhaustion and increased expression of PD-1, PD-L1.Targeting the PD-1/PD-L1 pathway could be a new approach to prevent malignant transformation from HT to PTC\&HT in the future.

Keywords: Papillary thyroid carcinoma, Nodular goiter , Hashimoto's thyroiditis, Lymph node metastasis, PD-1, Biomarker

\section{Introduction}

Thyroid cancer (TC) is the most common endocrine malignancy [1], and its incidence is steadily increasing over the past decades [2]. Papillary thyroid carcinoma (PTC) is the commonest subtype of TC [3]. Recent studies have confirmed that the annual increase in the incidence of TC is mainly due to the increase in the incidence of PTC, and is related to overdiagnosis [4]. The prognosis of PTC is good, however some patients are susceptible to lymph node metastasis, which is associated with poor prognosis. Few patients are insensitive to traditional surgery or develop postoperative recurrence. Therefore, it is important to discover new targets to improve the diagnosis and treatment of PTC. Immune cells play a vital role in the occurrence, development and prevention of tumors. Hashimoto's thyroiditis (HT) is the most common autoimmune disease characterized by the destruction of thyroid cells by leukocytes and antibody-mediated immune processes. Compared with the normal population, HT patients have a higher probability of developing TC, but its pathogenesis remains unclear [5]. Some clinical studies have found that thyroid dysfunction may occur after use of PD-1/ PD-L1 inhibitor [6]. In our previous study on the function of peripheral blood $\mathrm{T}$ cells in patients with papillary thyroid cancer, our team found that CD38 and HLA-DR molecules were increased in peripheral blood $\mathrm{T}$ cells of patients with papillary thyroid cancer and were associated with lymph node metastasis. It is suggested that there is immune imbalance in PTC patients and it is related to metastasis. Previous studies by other scholars have shown that, PD-L1 is related to the tumorigenesis and development of various cancers including PTC [7, 8]. In addition, Lubin [9] found that the expression of PD-L1 in papillary thyroid carcinoma caused by Hashimoto's thyroiditis increased. The purpose of this study was to evaluate the level of $\mathrm{T}$ cell exhaustion in patients with PTC, determine whether PTC\&HT can further promote the decline of $\mathrm{T}$ cell function and proliferation, and identify new diagnostic targets for PTC and PTC\&HT. Targeting the PD1/PD-L1 pathway may provide a new therapeutic strategy to treat PTC and prevent malignant transformation from HT to PTC\&HT in the future.

\section{Material and methods}

\section{Subjects}

Peripheral blood samples were drawn from 132 PTC patients and 48 nodular goiter (NG) patients, all of whom underwent thyroidectomy. The diagnosis of nodular goiter and thyroid cancer after operation was through histopathology. The diagnosis of HT was based on the increase of TPO and TGAb in combination with histopathological features, clinical examination and ultrasound examination. The control group consisted of 63 patients from the physical examination group, except for NG and HT. All the patients were from Taizhou Central Hospital between June 2020 and January 2021. 132 tissue sections of PTC and 48 tissue sections of NG were confirmed by two professional pathologists in line with the current WHO classification system to diagnose PTC and metastatic lesions. People with other tumors or tumor history were excluded from this study. None of the patients received chemotherapy or radiotherapy. The PTC population included 107 females and 25 males, and their age ranged from 22 to 80 years. There was no significant difference in age and gender among the PTC, NG and HP groups (Table 1). In addition, the patients' clinical stage, tumor stage, lymph node stage and extrathyroidal extension stage were listed according to the Tumor/Node/Metastasis (TNM) classification [10]. This study was approved by the Ethics Committee of Taizhou Central Hospital (Taizhou, PRC). Written formal consent was obtained from all subjects.

\section{Sample acquisition}

Venous blood samples were collected from all subjects in the morning after overnight fasting. $3 \mathrm{ml}$ of peripheral blood was collected from PTC, NG patients and HP and added to EDTA-K2 anticoagulant-containing tubes. The $\mathrm{T}, \mathrm{B}, \mathrm{NK}$ cells and PD-1 were analyzed by flow cytometry (BD FACSAria II, USA). Then, the peripheral blood was centrifuged at $3000 \mathrm{rpm}$, and the upper layer of plasma was drawn. The plasma levels of T3, T4, FT3, FT4, TSH, TGAb and TPO (thyroid function indexes) were determined by chemiluminescence immunoassay (CLIA) with biochemical instruments (SIEMENS ADVIA Centaur XP, GER).

\section{Flow cytometric analysis}

Peripheral blood and microspheres were incubated in the dark for $30 \mathrm{~min}$, hemolysin was added to destroy the red blood cells, then the sample was centrifuged to add PBS and analyzed immediately using BD FACSAria II cytometer and FlowJo software (BD, USA). Finally, the percentages of total $\mathrm{T}, \mathrm{CD}^{+} \mathrm{CD} 4^{+}, \mathrm{CD}^{+} \mathrm{CD} 8^{+} \mathrm{T}$ cells, 
Table 1 Papillary thyroid carcinoma patients' clinicopathological characteristics and laboratory data

\begin{tabular}{|c|c|c|c|c|c|c|c|}
\hline & PTC & NG & $\mathrm{HP}$ & $P$ & P1 & $P 2$ & P3 \\
\hline$n$ & 132 & 48 & 63 & & & & \\
\hline Age [year] & $49[22 \sim 80]$ & $52[29 \sim 71]$ & $47[26 \sim 74]$ & 0.06 & & & \\
\hline Gender & & & & 0.16 & & & \\
\hline Male & 25 & 6 & 17 & & & & \\
\hline Female & 107 & 42 & 46 & & & & \\
\hline \multicolumn{8}{|l|}{$\mathrm{T}$} \\
\hline $\mathrm{T} 1+\mathrm{T} 2$ & 130 & & & & & & \\
\hline $\mathrm{T} 3+\mathrm{T} 4$ & 2 & & & & & & \\
\hline \multicolumn{8}{|l|}{ N } \\
\hline NO & 83 & & & & & & \\
\hline $\mathrm{N} 1 \mathrm{a}+\mathrm{N} 1 \mathrm{~b}$ & 49 & & & & & & \\
\hline \multicolumn{8}{|l|}{ M } \\
\hline MO & 131 & & & & & & \\
\hline M1 & 1 & & & & & & \\
\hline \multicolumn{8}{|l|}{ Clinical stage } \\
\hline I & 122 & & & & & & \\
\hline$\|$ & 10 & & & & & & \\
\hline \multicolumn{8}{|l|}{ Laboratory data } \\
\hline $\mathrm{T} 3[\mathrm{nmol} / \mathrm{L}]$ & $1.18[1.06,1.28]$ & $1.23[1.12,1.31]$ & $1.21[1.12,1.31]$ & 0.23 & & & \\
\hline $\mathrm{T} 4[\mathrm{nmol} / \mathrm{L}]$ & $8.20[7.20,9.10]$ & $8.40[7.15,9.00]$ & $8.00[7.00,8.50]$ & 0.22 & & & \\
\hline FT3[pmol/L] & $3.36 \pm 0.41$ & $3.39 \pm 0.35$ & $3.22 \pm 0.36$ & $0.04^{*}$ & $0.03^{*}$ & $0.03^{*}$ & 0.61 \\
\hline $\mathrm{FT} 4[\mathrm{pmol} / \mathrm{L}]$ & $1.32 \pm 0.19$ & $1.34 \pm 0.17$ & $1.32 \pm 0.15$ & 0.69 & 0.92 & 0.44 & 0.43 \\
\hline $\mathrm{TSH}[\mu \mathrm{IU} / \mathrm{mL}]$ & $1.55[1.07,2.09]$ & $1.64[0.99,2.80]$ & $1.81[1.15,2.56]$ & 0.24 & & & \\
\hline TGAb [IU/mL] & $23.5[15.0,74.5]$ & $21.0[15.0,29.8]$ & $16.0[15.0,28.0]$ & $0.00^{*}$ & $0.00^{*}$ & 0.36 & 0.36 \\
\hline $\mathrm{TPO}[\mathrm{IU} / \mathrm{mL}]$ & $34.0[28.0,61.0]$ & $28.0[28.0,38.7]$ & $38.0[28.0,55.0]$ & 0.08 & & & \\
\hline $\mathrm{CD}^{+} \mathrm{PD}^{-1^{+}}(\%)$ & $11.5 \pm 4.7$ & $5.9 \pm 2.1$ & $8.6 \pm 4.5$ & $0.00^{*}$ & $0.00^{*}$ & $0.00^{*}$ & $0.00^{*}$ \\
\hline $\mathrm{CD}^{+} \mathrm{CD}^{+}{ }^{+} \mathrm{PD}-1^{+}(\%)$ & $7.9 \pm 3.2$ & $4.3 \pm 1.8$ & $6.43 \pm 2.7$ & $0.00^{*}$ & $0.00^{*}$ & $0.00^{*}$ & $0.00^{*}$ \\
\hline $\mathrm{CD}^{+} \mathrm{CD}^{+} \mathrm{PD}-1^{+}(\%)$ & $5.1[2.3,6.0]$ & $2.8[1.7,3.3]$ & $4.7[2.7,5.8]$ & $0.00^{*}$ & 0.75 & $0.00^{*}$ & $0.00^{*}$ \\
\hline
\end{tabular}

Data were expressed as mean \pm standard deviation (SD), median [interquartile range]. The continuous variables were compared by using the Student's t-test and the Mann-Whitney $U$ test, the categorical variables were compared by using the $X 2$ or Fisher's exact test between discovery and validation groups. $P$ :statistical difference within each group, P1: PTC and HP, P2: TN and HP, P3: PTC and TN

* represents significant differences $(p<0.05)$

NK cells, B cells, CD $4^{+} \mathrm{HLA}^{-\mathrm{DR}}{ }^{+}, \mathrm{CD} 8^{+} \mathrm{HLA}-\mathrm{DR}^{+}$, $\mathrm{CD} 8^{+} \mathrm{CD} 38^{+}$subsets, $\mathrm{CD} 3^{+} \mathrm{PD}-1^{+}, \mathrm{CD} 3^{+} \mathrm{CD} 4^{+} \mathrm{PD}-1^{+}$and $\mathrm{CD}^{+}{ }^{+} \mathrm{CD} 8^{+} \mathrm{PD}-1^{+}$were obtained. All the experiments were conducted according to the manufacturer's instructions.

\section{Immunohistochemistry}

Tissue sections were deparaffinized with xylene, then hydrated with alcohol, and antigen retrieval was performed by heating 0.01 sodium citrate buffer in a microwave oven for $15 \mathrm{~min}$. The sections were quenched with $0.3 \%$ hydrogen peroxide for 10 min to block endogenous peroxidase activity. They were incubated with the monoclonal antibody against PD-L1 (E1L3N, 1:200; Cell Signaling Technology, USA),CD3(SP7, 1:500; MXB
Biotechnology, PRC), PD-1(MX033, 1:500; MXB Biotechnology, PRC) overnight at $4{ }^{\circ} \mathrm{C}$, then added antirabbit secondary antibodies (1:500; Pierce, Appleton, WI, USA) and incubated at room temperature for 20 min. After each treatment, washed 3 times with PBS for 3 min each time, and then developed with 3,3-diaminobenzidine. After the sections were counterstained with hematoxylin and differentiated with hydrochloric acid and alcohol, they were dehydrated, transparent, and fixed. Random fields were chosen for imaging, which were performed with Zeiss photomicroscope (Carl Zeiss Meditec, Dublin, CA, USA). Two pathologists reviewed immunohistochemistry staining results. Quantitative analysis of PD-L1 expression was conducted on the basis of staining intensity and extent $(0$, no staining; $1+$, the 
total number of positive cells less than $25 \%$; $2+$, the total number of positive cells in 10-49\%; and $3+$, the total number of positive cells above 50\%). At least 5-10 HPFS were randomly observed.

\section{Statistical analysis}

All statistical analyses were conducted using SPSS v20.0 (IBM, USA) and GraphPad Prism8 (GraphPad Software, USA). If the data was normally distributed, mean \pm standard deviation (SD) was used to express the data, and one-way analysis of variance and independent sample t-test was used to analyze the data. If the data was non-normally distributed, the median $(\mathrm{Q} 25, \mathrm{Q} 75)$ was used to represent the data, and Kruskal-Wallis $\mathrm{H}$ test and Wilcoxon test was used to analyze the data. For data analysis between three groups, when one-way analysis of variance was used, further pairwise comparisons could be made irrespective of a significant difference. When the Kruskal-Wallis $\mathrm{H}$ test was used, further pairwise comparisons were made only when there was a significant difference between the three groups. A $p$-value < 0.05 was considered to be statistically significant.

\section{Results}

Clinicopathological characteristics and PD-1 expression in HP, NG and PTC groups

We examined the T3, T4, FT3, FT4, TSH, TGAb and TPO expression among the PTC group, NG group and HP group (Table 1, Fig. 1). The results showed that the expression of FT3 in the PTC group and NG group was

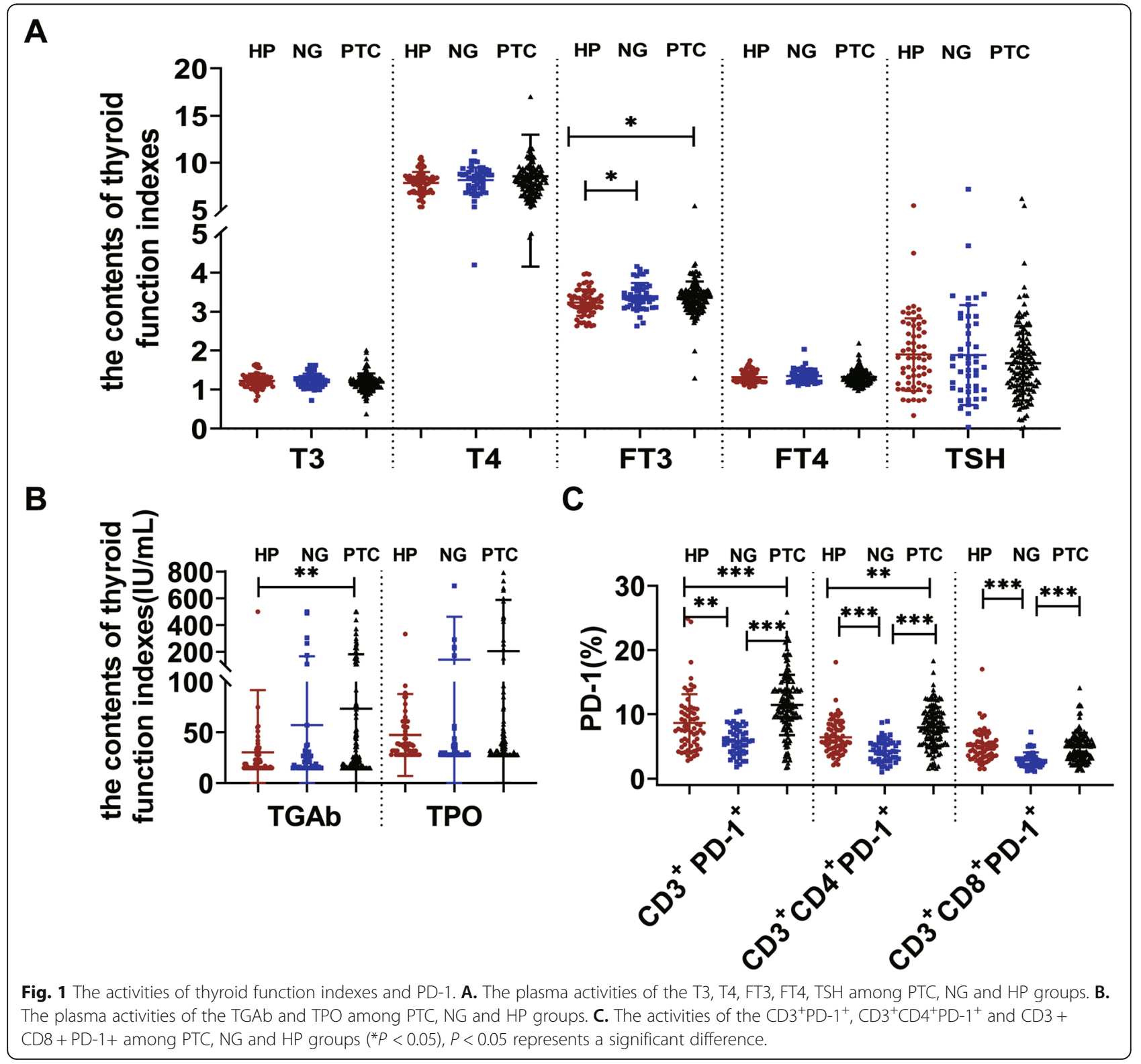


significantly higher than that in the HP group, while the expression of TGAb in the PTC group was significantly higher than that in the HP group $(p<0.05)$. The expression of $\mathrm{CD}^{+}{ }^{+} \mathrm{PD}-1^{+}$and $\mathrm{CD} 3^{+} \mathrm{CD} 4^{+} \mathrm{PD}-1^{+}$was significantly higher in the PTC group than in the HP group, while the expression of $\mathrm{CD}^{+}{ }^{\mathrm{PD}}-1^{+}, \mathrm{CD}^{+} \mathrm{CD} 4^{+} \mathrm{PD}-1^{+}$ and $\mathrm{CD} 3^{+} \mathrm{CD} 8^{+} \mathrm{PD}-1^{+}$was significantly lower in the NG group than in the HP group $(p<0.05)$ (Table 1, Fig. 1 , Fig. 3). The expression of $\mathrm{CD} 3^{+} \mathrm{PD}-1^{+}, \mathrm{CD} 3^{+} \mathrm{CD} 4^{+} \mathrm{PD}-1^{+}$ and $\mathrm{CD} 3^{+} \mathrm{CD} 8{ }^{+} \mathrm{PD}-1^{+}$in the PTC group was significantly different from that in the NG group $(p<0.05)$ (Table 1 , Fig. 1).

The expression of immune cells, thyroid function indexes and PD-1 in NG\&HT, PTC\&noHT and PTC\&HT groups

To determine the differences in immune cells, thyroid function indexes and PD-1 between PTC\&HT and PTC\&noHT, we detected the expression of immune cells, thyroid function indexes and PD-1 among the two groups. The expression of TGAb, TPO, $\mathrm{CD}^{+} \mathrm{PD}-1^{+}$,
$\mathrm{CD} 3^{+} \mathrm{CD} 4^{+} \mathrm{PD}-1^{+}$and $\mathrm{CD} 3^{+} \mathrm{CD} 8^{+} \mathrm{PD}-1^{+}$was significantly higher in the PTC\&HT group than in the PTC\&noHT group $(p<0.05)$ (Table 2, Fig. 2, Fig. 3). In addition, no significant difference was observed in other $\mathrm{T}, \mathrm{B}, \mathrm{NK}$ cells, T3, T4, FT3, FT4 and TSH among the two groups $(p>0.05)$.

In order to verify that $\mathrm{T}$ cell exhaustion in PTC was not completely caused by HT, we analyzed the expression of immune cells, thyroid function indexes and PD-1 in NG\&HT group and PTC\&HT group. The expression of $\mathrm{B}$ cell, $\mathrm{CD} 3^{+} \mathrm{PD}-1^{+}, \quad \mathrm{CD} 3^{+} \mathrm{CD} 4^{+} \mathrm{PD}-1^{+}$and $\mathrm{CD} 3^{+} \mathrm{CD} 8^{+} \mathrm{PD}-1^{+}$was significantly higher in the PTC\&HT group than that in the NG\&HT group $(p<$ 0.05) (Table 2, Fig. 2).

\section{T cells infiltration (TIL) in PTC microenvironment}

To comfirm the correlation between immune cell fraction of peripheral blood and thyroid tumor microenvironment, immunohistochemical staining was performed in 10 NG\&HT, 83 PTC\&noHT and 49 PTC\&HT tissue

Table 2 The changes of lymphocyte subsets, thyroid function indexes and PD-1 among NG\&HT, PTC\&noHT and PTC\&HT

\begin{tabular}{|c|c|c|c|c|c|c|c|}
\hline & NG\&HT $(n=10)$ & PTC\&noHT $(n=83)$ & PTC\&HT $(n=49)$ & $P$ & $P 1$ & $P 2$ & $P 3$ \\
\hline \multicolumn{8}{|c|}{ Laboratory Routine Data } \\
\hline Total T(\%) & $60.92 \pm 6.31$ & $63.49 \pm 8.49$ & $62.38 \pm 7.63$ & 0.565 & 0.451 & 0.706 & 0.387 \\
\hline $\mathrm{CD}^{+} \mathrm{CD}^{+}(\%)$ & $31.82 \pm 3.39$ & $37.24 \pm 6.79$ & $36.39 \pm 5.93$ & 0.132 & 0.047 & 0.093 & 0.523 \\
\hline $\mathrm{CD}^{+} \mathrm{CD}^{+}(\%)$ & $26.10 \pm 7.40$ & $22.99 \pm 7.40$ & $22.56 \pm 5.46$ & 0.443 & 0.273 & 0.201 & 0.614 \\
\hline $\mathrm{CD}^{+} / \mathrm{CD}^{+}(\%)$ & $1.21[0.90,1.78]$ & $1.64[1.19,2.37]$ & $1.69[1.25,2.18]$ & 0.235 & & & \\
\hline $\mathrm{CD}^{+} \mathrm{HLA}-\mathrm{DR}^{+}(\%)$ & $7.37 \pm 3.90$ & $5.96 \pm 2.06$ & $6.34 \pm 2.10$ & 0.266 & 0.128 & 0.417 & 0.250 \\
\hline $\mathrm{CD}^{+}{ }^{+} \mathrm{HLA}^{-\mathrm{DR}^{+}(\%)}$ & $7.98 \pm 3.96$ & $6.6 .5 \pm 3.88$ & $6.60 \pm 2.84$ & 0.633 & 0.376 & 0.341 & 0.834 \\
\hline $\mathrm{CD}^{+} \mathrm{CD} 8^{+}(\%)$ & $8.96 \pm 8.01$ & $5.42 \pm 2.81$ & $5.70 \pm 2.82$ & $0.032^{*}$ & $0.009^{*}$ & $0.016^{*}$ & 0.694 \\
\hline NK(\%) & $23.05 \pm 8.70$ & $17.24 \pm 8.20$ & $18.23 \pm 8.47$ & 0.233 & 0.100 & 0.186 & 0.484 \\
\hline$B(\%)$ & $10.85 \pm 2.89$ & $14.58 \pm 5.10$ & $15.33 \pm 4.71$ & 0.080 & 0.075 & $0.029^{*}$ & 0.281 \\
\hline T3(nmol/L) & $1.21[1.15,1.24]$ & $1.20[1.07,1.28]$ & $1.16[1.06,1.30]$ & 0.472 & & & \\
\hline $\mathrm{T} 4(\mathrm{nmol} / \mathrm{L})$ & $8.50[6.90,9.00]$ & $8.20[6.44,9.10]$ & $8.20[6.00,9.25]$ & 0.991 & & & \\
\hline FT3(pmol/L) & $3.28 \pm 0.23$ & $3.39 \pm 0.37$ & $3.32 \pm 0.48$ & 0.568 & 0.563 & 0.873 & 0.331 \\
\hline FT4(pmol/L) & $1.29 \pm 0.17$ & $1.30 \pm 0.18$ & $1.35 \pm 0.20$ & 0.350 & 0.882 & 0.466 & 0.162 \\
\hline $\mathrm{TSH}(\mu \mathrm{IU} / \mathrm{mL})$ & $1.98[1.49,4.69]$ & $1.43[1.02,1.94]$ & $1.79[1.17,2.46]$ & 0.155 & & & \\
\hline TGAb (IU/mL) & $218.0[29.0,489.0]$ & $18.0[15.00,23.0]$ & $125.0[33.0,243.5]$ & $0.000^{*}$ & $0.000^{*}$ & 0.543 & $0.000^{*}$ \\
\hline TPO (IU/mL) & $996.5[291.0,1300.0]$ & $28.0[28.0,37.5]$ & $258.0[36.0,909.0]$ & $0.000^{*}$ & $0.001^{*}$ & 0.165 & $0.000^{*}$ \\
\hline $\mathrm{CD}^{+} \mathrm{PD}^{-1^{+}}(\%)$ & $7.70 \pm 2.10$ & $10.35 \pm 4.13$ & $13.31 \pm 5.04$ & $0.000^{*}$ & $0.042^{*}$ & $0.006^{*}$ & $0.000^{*}$ \\
\hline $\mathrm{CD}^{+} \mathrm{CD}^{+}{ }^{+} \mathrm{PD}-1^{+}(\%)$ & $4.97 \pm 1.63$ & $7.12 \pm 2.93$ & $9.24 \pm 3.20$ & $0.000^{*}$ & $0.049^{*}$ & $0.003^{*}$ & $0.000^{*}$ \\
\hline $\mathrm{CD}^{+} \mathrm{CD}^{+}{ }^{+} \mathrm{PD}-1^{+}(\%)$ & $3.43 \pm 1.35$ & $4.53 \pm 2.13$ & $5.51 \pm 2.22$ & $0.012^{*}$ & 0.138 & $0.011^{*}$ & $0.005^{*}$ \\
\hline \multicolumn{8}{|l|}{ Immunohistochemistry } \\
\hline TILS(\%) & $1(10.0 \%)$ & $17(20.5 \%)$ & $24(49.0 \%)$ & $0.001^{*}$ & & & \\
\hline CD3 POSITIVE(\%) & $1(10.0 \%)$ & 13(15.6\%) & $21(42.9 \%)$ & $0.001^{*}$ & & & \\
\hline PD-1 POSITIVE(\%) & 0 & $12(14.5 \%)$ & $14(28.6 \%)$ & $0.038^{*}$ & & & \\
\hline
\end{tabular}


A

C
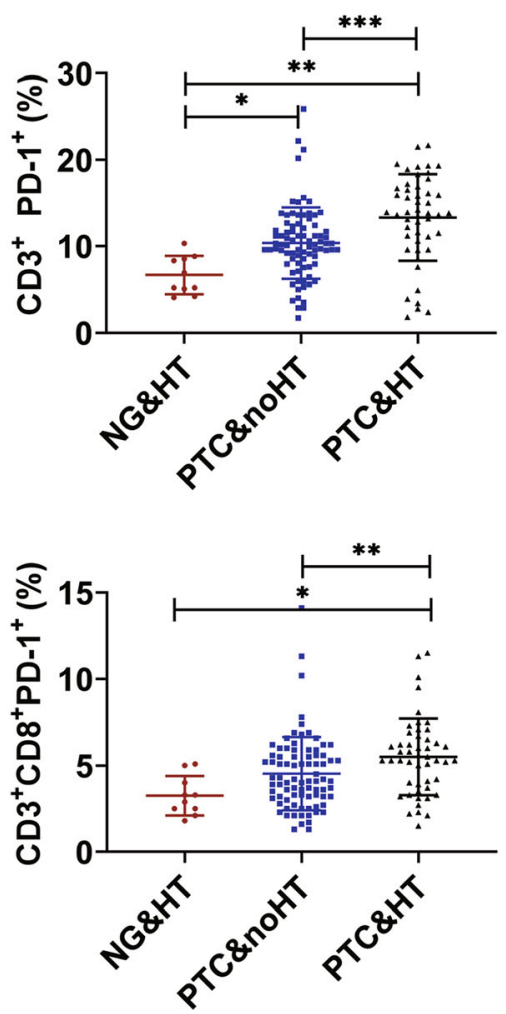

B

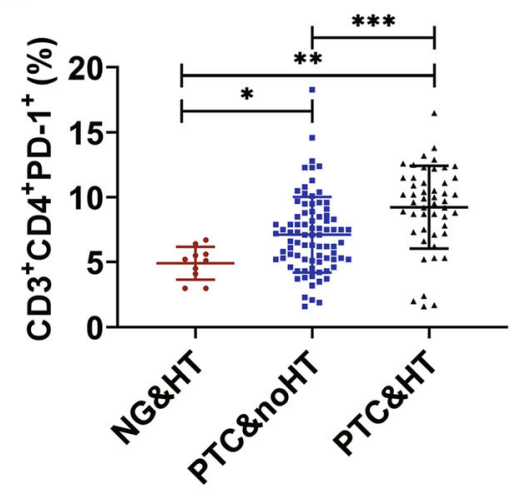

Fig. 2 The activities of PD-1. A. The activities of the CD3 + PD-1+ among NG\&HT, PTC\&noHT and PTC\&HT. B. The activities of the CD3 + CD4 + PD-1+ among NG\&HT, PTC\&noHT and PTC\&HT. C. The activities of the CD3 + CD8 + PD-1+ among NG\&HT, PTC\&noHT and PTC\&HT $\left({ }^{*} P<0.05\right)$

samples. The Positive proportions of TILS, CD3, PD-1 among the three groups were statistically significant. (Table 2, Fig. 4).

The expression of PD-L1 in NG\&noHT, NG\&HT, PTC\&noHT and PTC\&HT tissues

To verify whether the status of $\mathrm{T}$ cells in tumor microenvironment was consistent with that in peripheral blood, immunohistochemical staining of PD-L1 was performed in 9 PTC\&noHT, 10 NG\&noHT, 10 NG\&HT and 10 PTC\&HT tissue samples. PD-L1 was positive in 2 NG\&noHT (20\%), 7 NG\&HT (70\%), 5 PTC\&noHT (67\%) and 8 PTC\&HT (80\%).The expression of PD-L1 in PTC\&HT group was significantly higher than that in NG\&HT group, the expression of PD-L1 in PTC\&noHT group was significantly higher than that in NG\&noHT group $(p<0.05)$ (Table 3, Fig. 5, Fig. 6).

\section{PD-1 expression was associated with PTC lymph node metastasis}

To investigate whether PD-1, immune cells and thyroid function indexes are associated with PTC lymph node metastasis, we detected their expression levels. The expression of immune cells and thyroid function indexes showed no significant changes among the PTC N0 and PTC N1 stages $(p>0.05)$. In contrast, the expression of $\mathrm{CD}^{+} \mathrm{PD}-1^{+}$and $\mathrm{CD} 3^{+} \mathrm{CD} 4^{+} \mathrm{PD}-1^{+}$ in the PTC N1 group was significantly higher than that in the N0 group $(p<0.05)$ (Table 4 , Fig. 7$)$. The above results indicated that PD-1 might be a novel prognostic indicator of PTC.

\section{The relationship between PD-1 and the diagnosis of PTC}

Using PTC clinical diagnosis as the gold standard, the ROC curves of $\mathrm{CD} 3^{+} \mathrm{PD}-1^{+}, \mathrm{CD} 3^{+} \mathrm{CD} 4^{+} \mathrm{PD}-1^{+}$and $\mathrm{CD}^{+} \mathrm{CD} 8^{+} \mathrm{PD}-1^{+}$were drawn, with sensitivity as the ordinate and 1-specificity as the abscissa. The AUC values were compared. The AUC values were 0.770, 0,728 and 0.625, respectively (Fig. 8).

\section{Discussion}

$\mathrm{TC}$ is the most common endocrine malignant tumor, with the fifth highest incidence among female tumors [2]. PTC accounts for $85 \%$ of all types of TC. Recent studies have shown that cancer cells can escape immune 


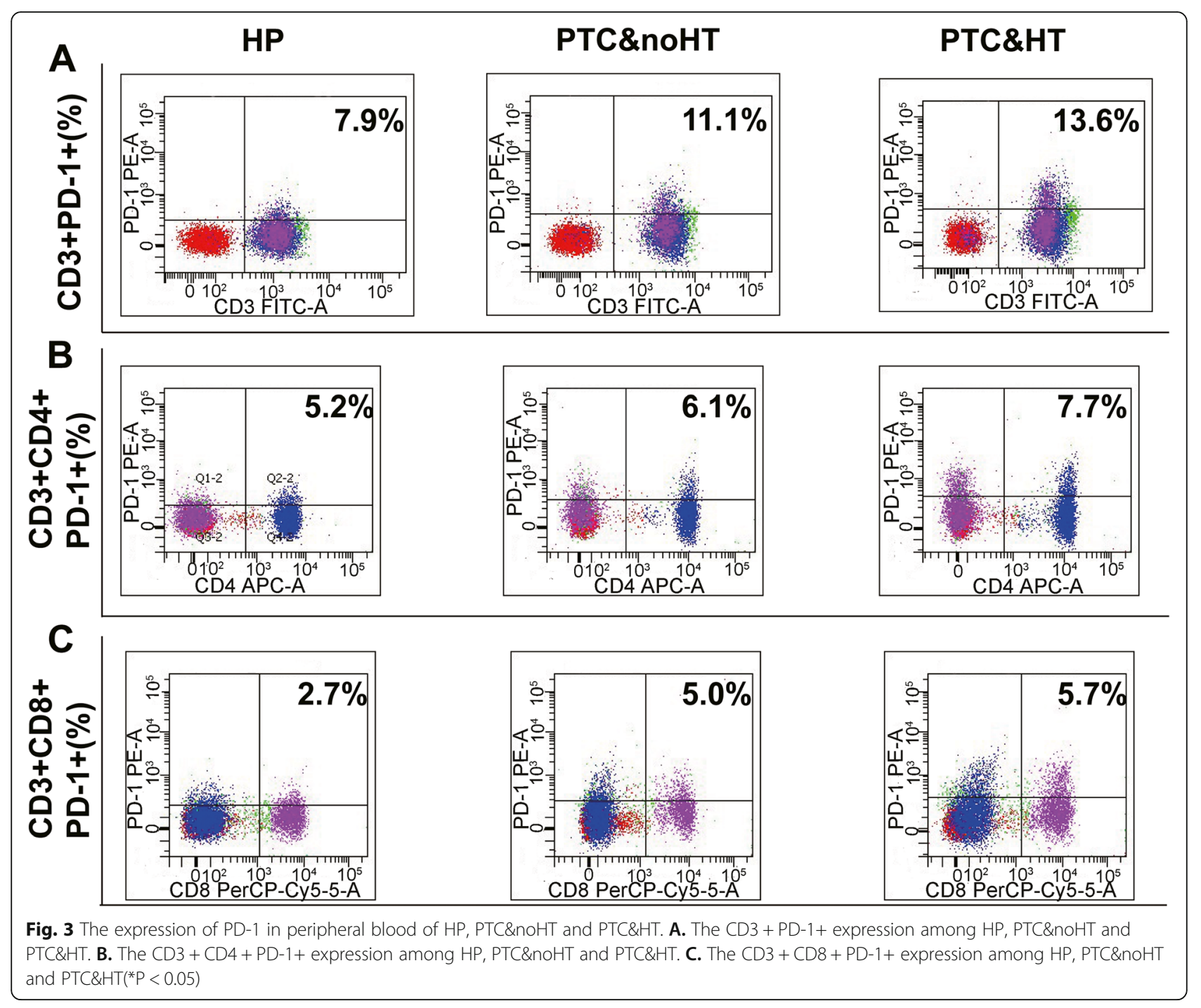

detection in the tumor microenvironment (TME). The normal microenvironment maintains tissue homeostasis and prevents the occurrence of tumors. Inflammatory mediators, reactive oxygen species, cytokines and chemokines from TME promote tumor growth. The relationship between TME and cancer cells is well established. The interaction between immune cells and cancer cells within TME contributes to all stages of cancer, starting from the early stage of tumorigenesis to the progression and metastasis of cancer $[11,12]$. T cell immunity plays an important role in the immunosuppressive pathway. However, the immunosuppressive mechanism in TME weakens the effector function of $\mathrm{T}$ cells [13].

Antigen-specific $\mathrm{T}$ cells are the key protective factors against cancer, but continuous antigen stimulation leads to $\mathrm{T}$ cell exhaustion. The function and proliferation of exhausted $\mathrm{T}$ cells decreases, partly due to the overexpression of inhibitory receptors such as PD-1. Inflammation is associated with TC, which raises key questions about the role of immune cells in its pathogenesis. There are numerous immune cells and mediators in the TC ecosystem. Our previous study showed that $\mathrm{CD} 8^{+} \mathrm{CD} 38^{+} \mathrm{T}$ cells act as immune activation novel biomarkers and early warning indicator of patients with PTC [14]. PD-1 is highly expressed in activated $\mathrm{T}$ cells, B cells, dendritic cells and natural killer cells $[15,16]$. Among immunosuppressive mechanisms, PD-1 has become the main marker of $\mathrm{T}$ cell dysfunction [7]. Many studies have shown that blocking the interaction between PD-1 and PD-L1 can reverse immune exhaustion and mediate anti-tumor activity [17-19]. PD-1 mainly restricts $\mathrm{T}$ cell activity in TME in the late stage of tumor 

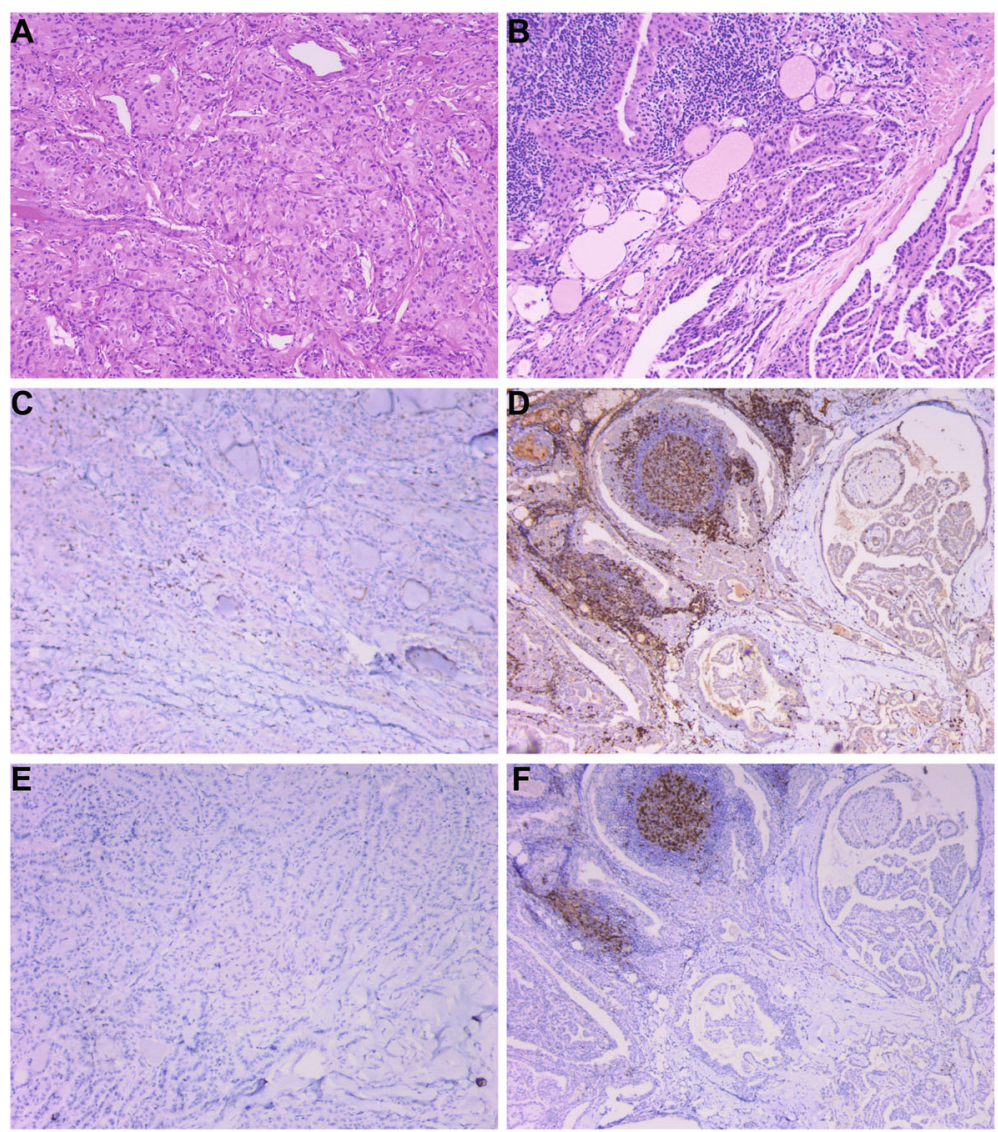

Fig. 4 The T cells infiltration in thyroid by immunohistochemistry. A. PTC\&noHT (100x). B. PTC\&HT (100x). C. The CD3 expression in PTC\&noHT (100x). D. The CD3 expression in PTC\&HT (100x). E. The PD-1 expression in PTC\&noHT (100x). F. The PD-1 expression in PTC\&HT (100X)

growth [20]. PD-1 is activated after binding to PD-L1, and recruits phosphatase SHP-2 close to T cell receptor (TCR) and costimulatory signal to block the activation of PI3K and Akt mediated by CD28 [21]. The expression of $\mathrm{PD}-\mathrm{L} 1$ and the status of cytotoxic $\mathrm{T}$ lymphocytes (CTL) in cancer patients are considered to be the decisive factors of their overall survival rate [22]. Blocking PD-1 pathway provides a new therapeutic approach for reinvigorating $\mathrm{T}$ cell response. In this study, the expression of $\mathrm{CD}^{+} \mathrm{PD}-1^{+}$and $\mathrm{CD}^{+} \mathrm{CD} 4^{+} \mathrm{PD}-1^{+}$weas significantly increased in the

Table 3 PD-L1 immunohistochemical staining results

\begin{tabular}{lllll}
\hline & NG\&noHT & NG\&HT & PTC\&noHT & PTC\&HT \\
\hline$N$ & 10 & 10 & 9 & 10 \\
0 & 8 & 3 & 3 & 2 \\
$1+$ & 2 & 3 & 3 & 0 \\
$2+$ & 0 & 4 & 3 & 2 \\
$3+$ & 0 & 0 & 0 & 6 \\
\hline
\end{tabular}

NG and PTC groups, and the expression of PD-1 was significantly higher in PTC patients in N1 stage than those in N0 stage.

Many recent studies have confirmed the correlation between thyroid autoimmune diseases and the incidence of PTC. HT is the most common autoimmune disease characterized by the destruction of thyroid cells by leukocytes and antibody-mediated immune processes. It causes chronic inflammation of the thyroid tissue. Many studies have demonstrated the relationship between PTC and HT. Fiore et al. [23] found that the prevalence of PTC is higher in patients with nodular-HT than in patients with nodular goiter. Moreover, $5-10 \%$ of patients with both PTC and HT may develop aggressive disease and require systemic treatment [24]. Both TPO and TgAb are independent risk factors for TC. TPO is the enzyme responsible for the production of thyroid hormones. Li et al. [25] found that positive TGAb might be a risk factor for cervical lymph node metastasis. In this study, the expression of TPO and TGAb was significantly higher 

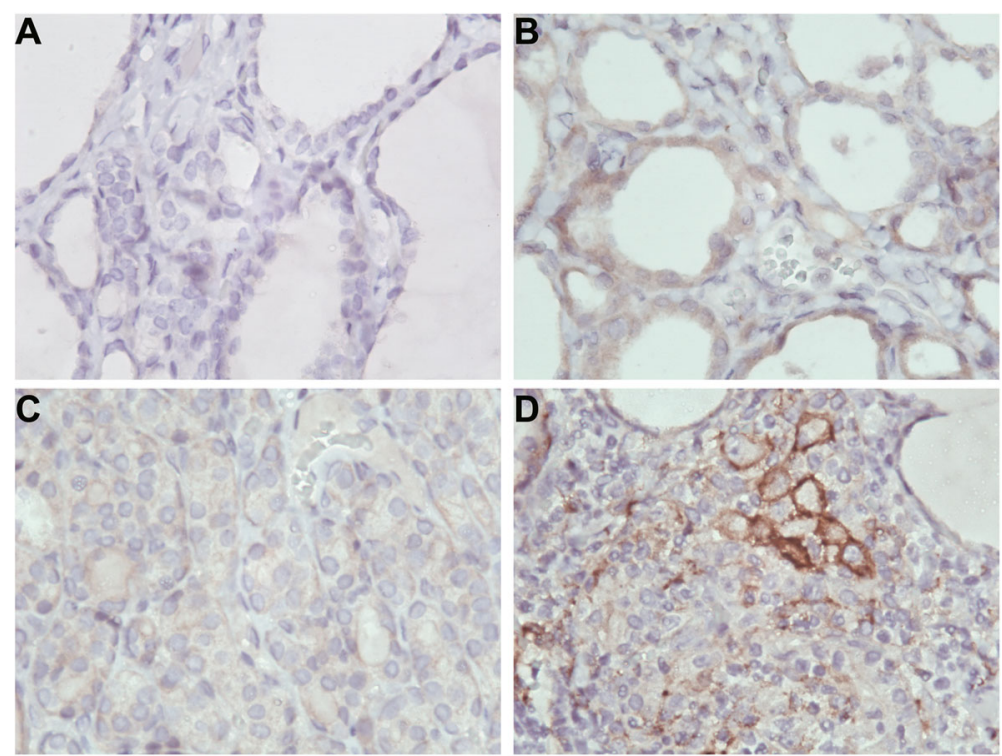

Fig. 5 The expression of PD-L1 in NG\&noHT, NG\&HT, PTC\&noHT and PTC\&HT tissues. A. NG\&noHT (400X). B. NG\&HT (400X). C. PTC\&noHT (400X). D. PTC\&HT (400x)

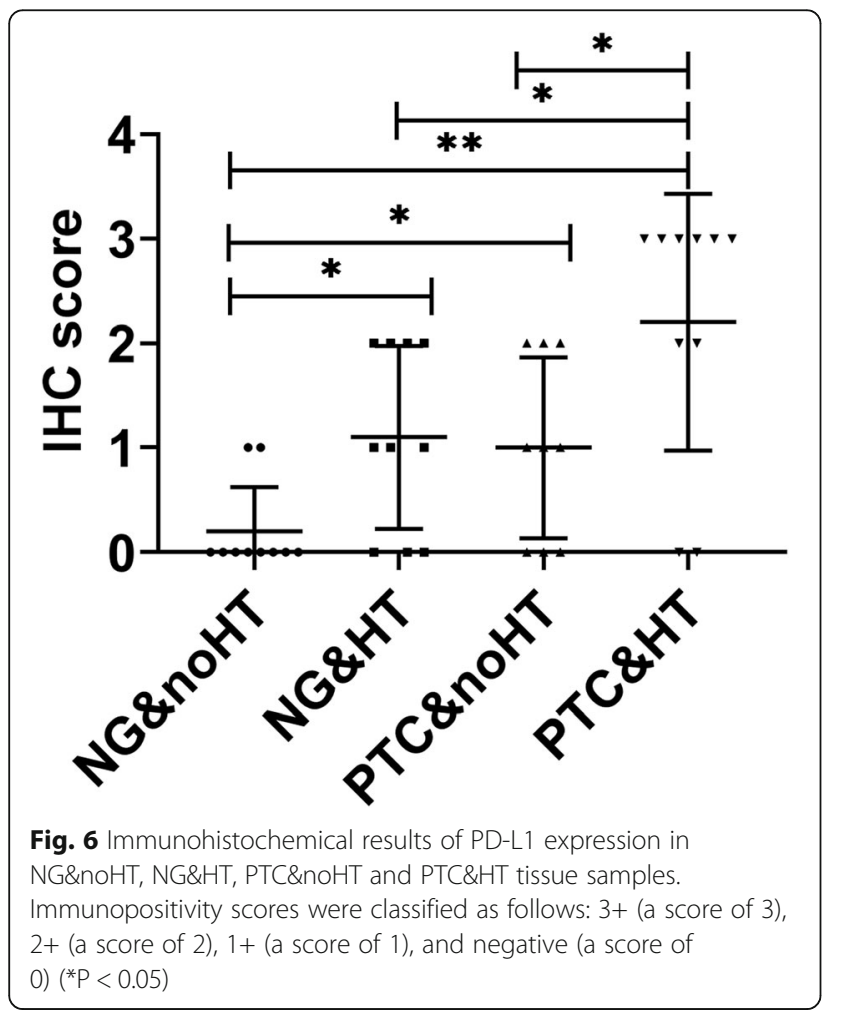

Table 4 Correlation between lymphocyte subsets, thyroid function index and lymph node metastasis of PTC patients

\begin{tabular}{|c|c|c|c|}
\hline & No $(n=83)$ & $\mathrm{N} 1(n=49)$ & $P$ \\
\hline Total T(\%) & $63.17 \pm 7.26$ & $62.92 \pm 9.59$ & 0.877 \\
\hline $\mathrm{CD}^{+} \mathrm{CD}^{+}(\%)$ & $36.58 \pm 6.41$ & $37.50 \pm 6.60$ & 0.436 \\
\hline $\mathrm{CD}^{+} \mathrm{CD}^{+}(\%)$ & $23.28 \pm 6.27$ & $22.07 \pm 7.44$ & 0.321 \\
\hline $\mathrm{CD}^{+} / \mathrm{CD}^{+}(\%)$ & $1.64[1.24,2.12]$ & $1.76[1.23,2.32]$ & 0.382 \\
\hline $\mathrm{CD}^{+} \mathrm{HLA}^{-\mathrm{DR}^{+}(\%)}$ & $6.06 \pm 2.05$ & $6.16 \pm 2.14$ & 0.802 \\
\hline $\mathrm{CD}^{+} \mathrm{HLA}^{-\mathrm{DR}^{+}(\%)}$ & $6.70[4.60,9.05]$ & $6.00[3.60,7.30]$ & 0.059 \\
\hline $\mathrm{CD}^{+} \mathrm{CD}^{-} 8^{+}(\%)$ & $4.80[3.40,6.45]$ & $5.40[3.50,8.60]$ & 0.084 \\
\hline NK(\%) & $17.81 \pm 7.46$ & $17.26 \pm 9.59$ & 0.715 \\
\hline $\mathrm{B}(\%)$ & $14.76 \pm 4.75$ & $15.01 \pm 5.33$ & 0.776 \\
\hline $\mathrm{T} 3(\mathrm{nmol} / \mathrm{L})$ & $1.18 \pm 0.22$ & $1.20 \pm 0.23$ & 0.596 \\
\hline $\mathrm{T} 4(\mathrm{nmol} / \mathrm{L})$ & $8.30[7.15,9.15]$ & $8.00[7.30,8.80]$ & 0.606 \\
\hline FT3(pmol/L) & $3.38[3.14,3.52]$ & $3.37[3.20,3.57]$ & 0.655 \\
\hline FT4(pmol/L) & $1.33 \pm 0.20$ & $1.31 \pm 0.17$ & 0.670 \\
\hline TSH $(\mu \mathrm{IU} / \mathrm{mL})$ & $1.65 \pm 0.92$ & $1.71 \pm 1.01$ & 0.766 \\
\hline TGAb (IU/mL) & $25.00[15.50,78.00]$ & $22.00[15.00,52.00]$ & 0.363 \\
\hline TPO (IU/mL) & $37.00[28.00,74.00]$ & $30.00[28.00,52.00]$ & 0.188 \\
\hline $\mathrm{CD}^{+} \mathrm{PD}^{-1^{+}}(\%)$ & $10.76 \pm 4.68$ & $12.63 \pm 4.52$ & $0.026^{*}$ \\
\hline $\mathrm{CD}^{+} \mathrm{CD}^{+}{ }^{+} \mathrm{PD}-1^{+}(\%)$ & $7.27 \pm 3.01$ & $8.98 \pm 3.24$ & $0.003^{*}$ \\
\hline $\mathrm{CD}^{+} \mathrm{CD}^{+} \mathrm{PD}-1^{+}(\%)$ & $4.66 \pm 1.81$ & $5.29 \pm 2.73$ & 0.156 \\
\hline
\end{tabular}

* represents significant differences $(p<0.05)$ 
A

B

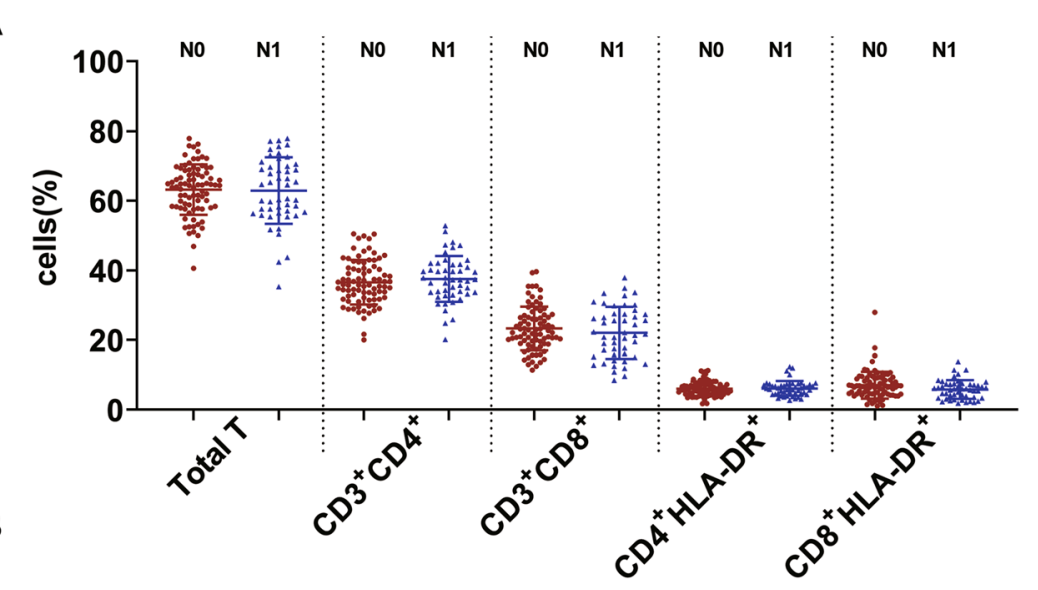

C
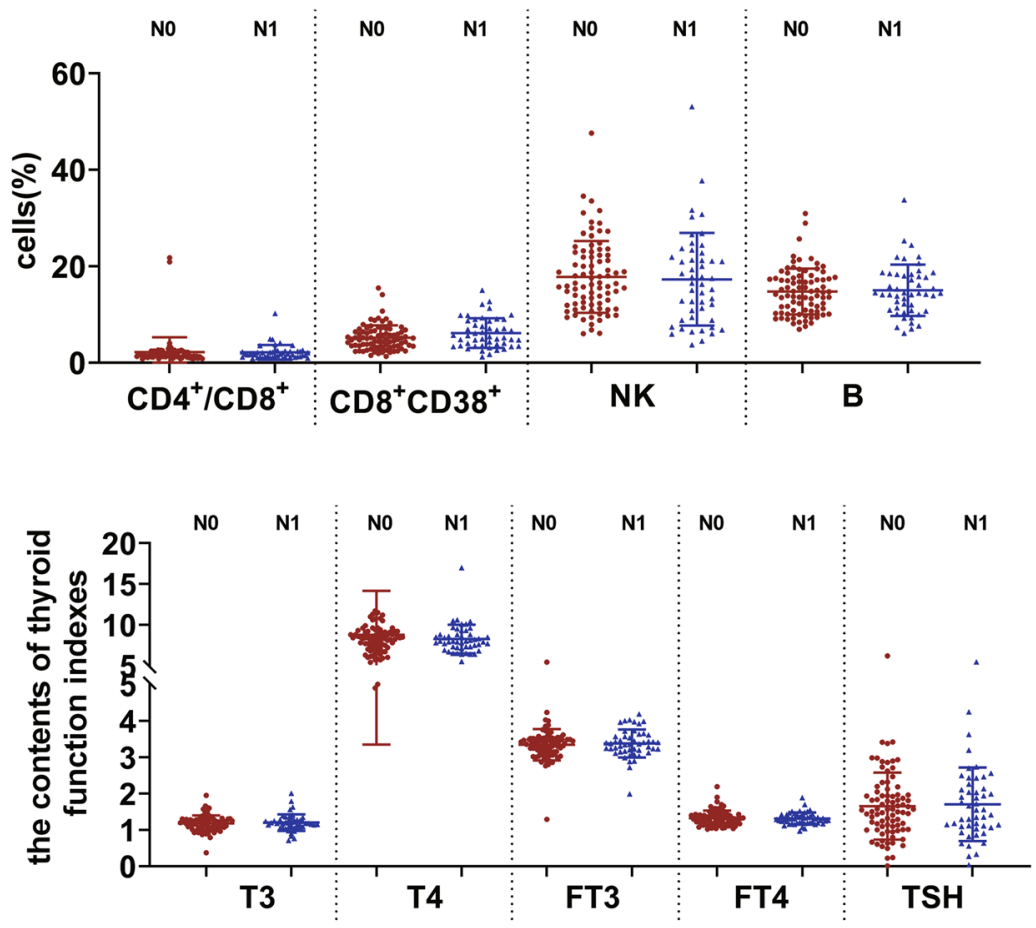

D

E
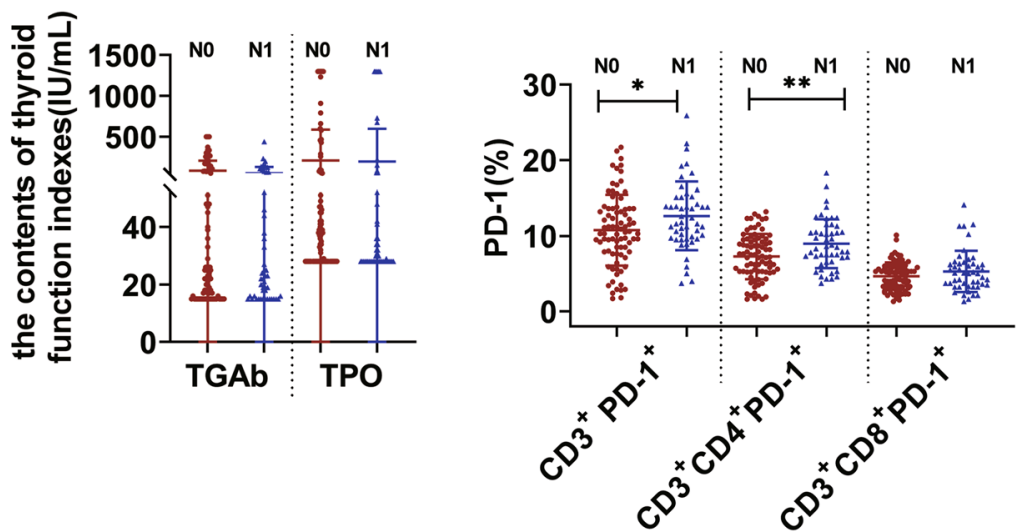

Fig. 7 (See legend on next page.) 
(See figure on previous page.)

Fig. 7 The activities of the NK cell, B cell, T cell subset, thyroid function indexes and PD-1. A. The activities of the Total T cells, CD3 + CD4+, $\mathrm{CD} 3+\mathrm{CD} 8+, \mathrm{CD} 4+\mathrm{HLA}-\mathrm{DR}+$ and CD8 + HLA-DR+ cells among N0 and N1. B. The activities of the CD4+/CD8+, CD8 + CD38+ cells, NK and B cells among N0 and N1. C. The plasma activities of the T3, T4, FT3, FT4, TSH among N0 and N1. D. The plasma activities of the TGAb and TPO among $\mathrm{N} 0$ and N1. E. The activities of the CD3 + PD-1+, CD3 + CD4 + PD-1+ and CD3 + CD8 + PD-1+ among N0 and N1 (*P $<0.05)$

in the PTC\&HT group than in the PTC group. However, there was no significant difference between thyroid function indexes and PTC lymph node metastasis. Meanwhile, we found that the expression of $\mathrm{CD}^{+}{ }^{+} \mathrm{PD}-1^{+}, \mathrm{CD}^{+}{ }^{+} \mathrm{CD} 4^{+} \mathrm{PD}-1^{+}$and $\mathrm{CD} 3^{+} \mathrm{CD} 8^{+} \mathrm{PD}-$ $1^{+}$was significantly higher in PTC\&HT patients than in PTC without HT patients. In addition, to verify whether T cell exhaustion in PTC arise from HT, we analyzed the expression of immune cells and PD-1 in NG\&HT and PTC\&HT, and found that the expression of $\mathrm{B}$ cells, $\mathrm{CD} 3^{+} \mathrm{PD}-1^{+}, \mathrm{CD} 3^{+} \mathrm{CD} 4^{+} \mathrm{PD}-1^{+}$and $\mathrm{CD}^{+}{ }^{+} \mathrm{CD} 8^{+} \mathrm{PD}-1^{+}$in PTC\&HT was significantly higher than that in NG\&HT group. The results of immunohistochemistry also confirmed the above results of peripheral blood, and there were significant differences in the expression of PD-L1 between PTC and NG, as well as between PTC\&HT and NG\&HT. The above results suggested that PD-1 might act as an early warning indicator of the progression of HT patients to PTC.

In this study, we measured the expression of $\mathrm{CD}^{+} \mathrm{CD}^{+}, \mathrm{CD}^{+} \mathrm{CD}^{+} \mathrm{T}$ cells, NK cells, $\mathrm{B}$ cells,

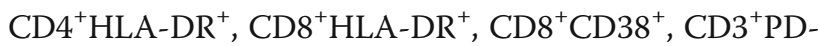
$1^{+}, \mathrm{CD}^{+}{ }^{+} \mathrm{CD} 4^{+} \mathrm{PD}-1^{+}$and $\mathrm{CD} 3^{+} \mathrm{CD} 8^{+} \mathrm{PD}-1^{+}$by flow cytometry, and T3, T4, FT3, FT4, TSH, TGAb and TPO by CLIA among PTC group, NG group and HP group to determine whether they were related to the progression of PTC. We also explored the differences in $\mathrm{CD}^{+} \mathrm{CD} 4^{+}$, $\mathrm{CD}^{+}{ }^{+} \mathrm{CD} 8^{+} \mathrm{T}$ cells, NK cells, B cells, CD $4^{+} \mathrm{HLA}^{+} \mathrm{DR}^{+}$, $\mathrm{CD} 8^{+} \mathrm{HLA}^{-} \mathrm{DR}^{+}, \quad \mathrm{CD} 8^{+} \mathrm{CD} 38^{+}$subsets, $\mathrm{CD} 3^{+} \mathrm{PD}-1^{+}$, $\mathrm{CD}^{+}{ }^{+} \mathrm{CD} 4^{+} \mathrm{PD}^{-} 1^{+}$and $\mathrm{CD} 3^{+} \mathrm{CD} 8{ }^{+} \mathrm{PD}-1^{+}, \mathrm{T} 3, \mathrm{~T} 4, \mathrm{FT} 3$, FT4, TSH, TGAb and TPO expression between the PTC\&HT group and the PTC group.

There are still some limitations in this research. This research is a retrospective study. Our data analysis was limited to clinical parameters and the exact geographic location of the samples collected. In addition, we did not carry out in vitro and in vivo experiments. It is planned to explore the key molecules and mechanism of $\mathrm{HT}$ to PTC in future research.

In summary, PTC has a certain degree of $\mathrm{T}$ cell exhaustion, especially complicated with $\mathrm{HT}$. PD- $1^{+} \mathrm{T}$ cells might act as a biomarker for the differential diagnosis of PTC and NG. PD-1 might be used as an early warning

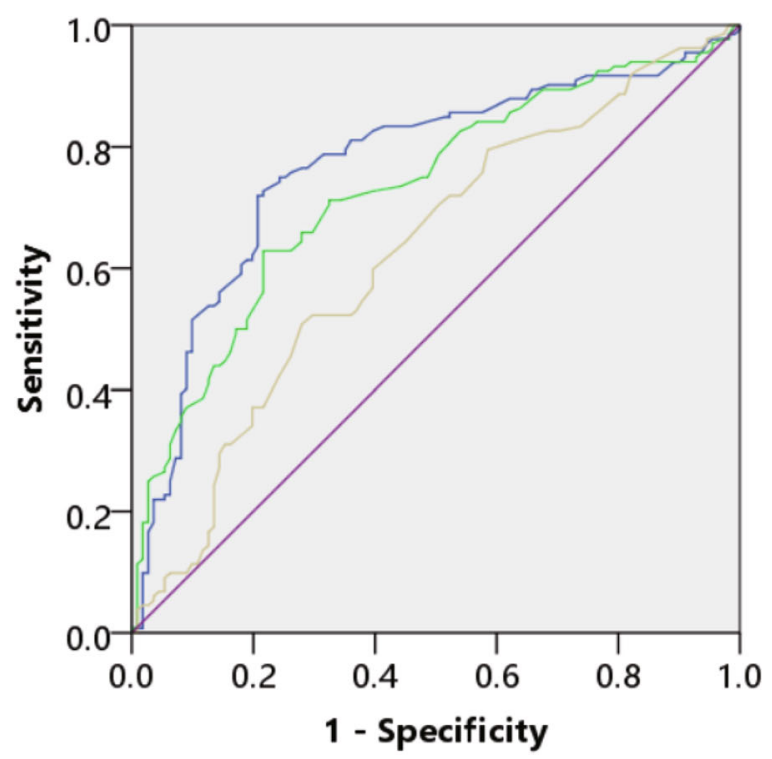

Source of the curve

$-\mathrm{CD} 3+\mathrm{PD}-1+$

$-\mathrm{CD} 3+\mathrm{CD} 4+\mathrm{PD}-1+$

- $\mathrm{CD} 3+\mathrm{CD} 8+\mathrm{PD}-1+$

- Reference Line 
biomarker for the progression of HT to PTC. Targeting the PD-1 pathway could be a new approach to treat PTC and prevent malignant transformation from HT to PTC\&HT in the future.

\section{Acknowledgements}

Not applicable.

\section{Authors' contributions}

Chumeng Zhu: visualization, methodology, and writing-original draft. Yuechu Dai: resources. Hui Zhang: methodology and writing-original draft. Yanyun Ruan: data curation, and validation. Yong Zhou: resources. Yingjie Dai: methodology. Lilong Fan: software and validation. Tianjun Jia: conceptualization, and writing-review and editing. Hongsheng Lu: data curation, funding acquisition, and writing-review and editing. Qi Chen: funding acquisition, project administration, and writing -review and editing. The author(s) read and approved the final manuscript

\section{Funding}

This work was supported in part by the Foundation of the Zhejiang Health Commission (No. 2019KY791) (No. 2020RC041), (No. 2021KY1219),

Department of Science and Technology of Zhejiang province, (No.

LGF20H160029), (No. LGD20H160004).

Availability of data and materials

The data used to support the findings of this study are included within the article.

\section{Declarations}

\section{Ethics approval and consent to participate}

This study was approved by Ethics Committee of Taizhou Central Hospital. Written informed consent was obtained from each individual in the study.

\section{Competing interests}

No conflict of interest exits in the submission of this manuscript, and manuscript is approved by all authors for publication.

\section{Author details \\ 'Precision Medicine Center, Taizhou Central Hospital (Taizhou University Hospital), Taizhou 318000, Zhejiang, People's Republic of China. ${ }^{2}$ College of Lab Medicine, Hebei North University, No.11, Zuanshi Road (south), Gaoxin District, Zhangjiakou 075000, Hebei, People's Republic of China. ${ }^{3}$ Department of Surgical Oncology, Taizhou Central Hospital (Taizhou University Hospital), Taizhou, 318000 Zhejiang, People's Republic of China. ${ }^{4}$ Department of Pathology, Taizhou Central Hospital (Taizhou University Hospital), Taizhou, 31800 Zhejiang, People's Republic of China. ${ }^{5}$ Clinical Laboratory, Taizhou Central Hospital (Taizhou University Hospital), Taizhou, 318000 Zhejiang, People's Republic of China.}

Received: 8 March 2021 Accepted: 12 August 2021

Published online: 31 August 2021

\section{References}

1. Sung H, Ferlay J, Siegel RL, Laversanne M, Soerjomataram I, Jemal A, Bray F. Global Cancer Statistics 2020: GLOBOCAN Estimates of Incidence and Mortality Worldwide for 36 Cancers in 185 Countries. CA Cancer J Clin. 2021;71(3):209-249.

2. Bray F, Ferlay J, Soerjomataram I, et al. Global cancer statistics 2018: GLOBOCAN estimates of incidence and mortality worldwide for 36 cancers in 185 countries. CA Cancer J Clin. 2018:68(6):394-424.

3. Fagin JA, Wells SA. Biologic and clinical perspectives on thyroid Cancer. N Engl J Med. 2016;375(23):2307.

4. Seib CD, Sosa JA. Evolving understanding of the epidemiology of thyroid Cancer. Endocrinol Metab Clin N Am. 2019:48(1):23-35.

5. Zeng R, Zhao M, Niu H, et al. Relationship between Hashimoto's thyroiditis and papillary thyroid carcinoma in children and adolescents. Eur Rev Med Pharmacol Sci. 2018:22(22):7778-87.

6. Basak EA, van der Meer JWM, Hurkmans DP, et al. Overt thyroid dysfunction and anti-thyroid antibodies predict response to anti-PD-1 immunotherapy in Cancer patients. Thyroid. 2020;30(7):966-73.

7. Thommen DS, Schumacher TN. T cell dysfunction in Cancer. Cancer Cell. 2018;33(4):547-62.
8. French JD, Kotnis GR, Said S, et al. Programmed death-1+ T cells and regulatory $T$ cells are enriched in tumor-involved lymph nodes and associated with aggressive features in papillary thyroid cancer. J Clin Endocrinol Metab. 2012;97(6):E934-43.

9. Lubin D, Baraban E, Lisby A, et al. Papillary thyroid carcinoma emerging from Hashimoto thyroiditis demonstrates increased PD-L1 expression, which persists with metastasis. Endocr Pathol. 2018;29(4):317-23.

10. Kim HI, Kim K, Park SY, et al. Refining the eighth edition AJCC TNM classification and prognostic groups for papillary thyroid cancer with lateral nodal metastasis. Oral Oncol. 2018;78:80-6.

11. Joyce JA, Fearon DT. T cell exclusion, immune privilege, and the tumor microenvironment. Science. 2015;348(6230):74-80.

12. Ferrari SM, Fallahi P, Galdiero MR, Ruffilli I, Elia G, Ragusa F, Paparo SR, Patrizio A, Mazzi V, Varricchi G, Marone G, Antonelli A. Immune and Inflammatory Cells in Thyroid Cancer Microenvironment. Int J Mol Sci. 2019;20(18):4413.

13. Chen DS, Mellman I. Oncology meets immunology: the cancer-immunity cycle. Immunity. 2013;39(1):1-10.

14. Lu H, Zhang L, Dai Y, et al. Markers of immune activation: novel biomarkers to predict the early-warning indicator of patients with papillary thyroid carcinoma. Diagn Pathol. 2020;15(1):16.

15. Agata $Y$, Kawasaki A, Nishimura $H$, et al. Expression of the PD-1 antigen on the surface of stimulated mouse T and B lymphocytes. Int Immunol. 1996;8(5):765-72.

16. Keir ME, Butte MJ, Freeman GJ, et al. PD-1 and its ligands in tolerance and immunity. Annu Rev Immunol. 2008;26:677-704.

17. Tumeh PC, Harview CL, Yearley JH, et al. PD-1 blockade induces responses by inhibiting adaptive immune resistance. Nature. 2014;515(7528):568-71.

18. Ohaegbulam KC, Assal A, Lazar-Molnar E, et al. Human cancer immunotherapy with antibodies to the PD-1 and PD-L1 pathway. Trends Mol Med. 2015;21(1):24-33.

19. Cha JH, Chan LC, Li CW, et al. Mechanisms controlling PD-L1 expression in Cancer. Mol Cell. 2019;76(3):359-70.

20. Fife BT, Bluestone JA. Control of peripheral T-cell tolerance and autoimmunity via the CTLA-4 and PD-1 pathways. Immunol Rev. 2008;224:166-82.

21. Salama AD, Chitnis T, Imitola J, et al. Critical role of the programmed death1 (PD-1) pathway in regulation of experimental autoimmune encephalomyelitis. J Exp Med. 2003;198(1):71-8.

22. Kato T, Noma K, Ohara T, et al. Cancer-associated fibroblasts affect Intratumoral CD8(+) and FoxP3(+) T cells via IL6 in the tumor microenvironment. Clin Cancer Res. 2018:24(19):4820-33.

23. Fiore $E$, Rago T, Latrofa F, et al. Hashimoto's thyroiditis is associated with papillary thyroid carcinoma: role of TSH and of treatment with L-thyroxine. Endocr Relat Cancer. 2011;18(4):429-37.

24. Ferri C, Sebastiani M, Giuggioli D, et al. Hepatitis C virus syndrome: a constellation of organ- and non-organ specific autoimmune disorders, B-cell non-Hodgkin's lymphoma, and cancer. World J Hepatol. 2015;7(3):327-43.

25. Li W, Ming H, Sun D, et al. The relationship between BRAFV600E, NF-kappaB and TgAb expression in papillary thyroid carcinoma. Pathol Res Pract. 2017;213(3):183-8.

\section{Publisher's Note}

Springer Nature remains neutral with regard to jurisdictional claims in published maps and institutional affiliations.
Ready to submit your research? Choose BMC and benefit from:

- fast, convenient online submission

- thorough peer review by experienced researchers in your field

- rapid publication on acceptance

- support for research data, including large and complex data types

- gold Open Access which fosters wider collaboration and increased citations

- maximum visibility for your research: over $100 \mathrm{M}$ website views per year

At $\mathrm{BMC}$, research is always in progress.

Learn more biomedcentral.com/submissions 